Miroslav Neslusan - Jan Moravec*

\title{
INFLUENCE OF COMPONENTS BENDING ON THE CONSEGUTIVE PLASMA NITRIDATION AND BARKHAUSEN NOISE EMISSION
}

This paper deals with the non destructive evaluation of components after the plasma nitridation via the Barkhausen noise techniques. Effect of different surface states before the plasma nitriding is studied via the non destructive Barkhausen noise technique, as well as the conventional destructive techniques. Bending of flat samples to different bending angles was performed and magnetic, as well as conventional destructive testing, was carried out on the outer, inner and flat surfaces. The results of experiments show that the Barkhausen noise emission is a function of the heat treatment, whereas intensity of bending and the corresponding deformation are only minor. The different states of the surface before the plasma nitriding result into the similar thickness of the compound layer. Furthermore, the underlying diffusion of near the surface layer state is different.

Keywords: bending, plasma nitridation, Barkhausen noise

\section{Introduction}

Nitriding is the outstanding concept in which the hard surface is mixed with the tough core. Nitriding thermo chemical process is usually conducted to improve fatigue life, wear or corrosion resistance of the components' surface [1-4]. High hardness of nitrided layers originates from hard nitride micro precipitates due to low solubility of nitrogen in $\alpha$-iron. Nitrogen is produced by decomposition of ammonia $\mathrm{NH}_{3}$ atmosphere and diffusion layer (as the main nitriding region) is coated by the adjoining compound layer. The diffusion layer usually contains small volume of nitrogen dissolved in $\alpha$-iron together with the facecentered cubic $\gamma^{\prime}$-nitride $\mathrm{Fe}_{4} \mathrm{~N}$ and hexahedral $\varepsilon$-nitride $\mathrm{Fe}_{2-3} \mathrm{~N}$ (sometimes orthorhombic $\zeta$-nitride $\mathrm{Fe}_{2} \mathrm{~N}$ ) [2]. On the other hand, the compound layer is entirely composed of $\varepsilon$ and $\gamma^{\prime}$ nitrides its thickness is much less compared to diffusion one. Nitriding is widely used in the automotive industry, in the forging industry for the enhancement of forge dies and in the die-casting industry. As opposed to the carburizing, nitriding requires the lowest temperatures (up to $550{ }^{\circ} \mathrm{C}$ ) of all the thermo chemical diffusion techniques [2]. This means that steel does not undergo any phase transformations. Moreover, the high hardness of nitrided layers is initiated directly during the diffusion process, whereas case carburized components require subsequent heat treatment. On the other hand, nitriding cannot be completed in the cycle time of the carburizing process. The nitriding process can be carried out in a variety of manners. Except gaseous, salt bath or fluidized bed, the plasma nitriding is widely used in many real industrial applications, as well. The physical principle of this procedure is based on the glow discharge plasma assisted decomposition of $\mathrm{N}_{2}$. The surface is heated by bombardment with highly energetic positive ions in the plasma.

\footnotetext{
* Miroslav Neslusan, Jan Moravec

Faculty of Mechanical Engineering, University of Zilina, Slovakia

E-mail: mirolav.neslusan@fstroj.uniza.sk
}

As opposed to the conventional gas nitriding, plasma nitriding produced compound layer free of porous, better dimensional accuracy of components, higher ductility of nitrided layers, better mechanical properties, surface free annealing and remarkable reduction in the nitriding time. Numerous investigations focused on plasma nitriding procedure have been conducted using various nitriding regimes as well as materials. Marot at al. [5] found that improved nitrogen transport can be obtained after nitridation in $\mathrm{NH}_{3}$ plasma without cathodic bias on the samples. Such cold conditions allow the iron matrix to be nitrided in a depth range of $100-400 \mu \mathrm{m}$ at a temperature as low as $350^{\circ} \mathrm{C}$.

The main disadvantage of the plasma nitriding can be viewed in more complex process control due to many parameters affecting metallurgy of nitrided components, such as nitriding time, temperature of the workpiece and chamber, process gas, work and support fixturing area, power voltage, current density, vacuum level, pulses duration, etc. For this reason, the plasma nitriding process needs quite a sophisticated process control, as well as the post processing validation in which the plasma nitridation parameters are correlated with the surface state of components, expressed in such terms as thickness of diffusion and compound layers, their chemistry, hardness profile, surface defects, etc. For instance, Flori at al. [6] analyzed an industrial plasma-nitrided sample which was detected having two types of defects: an external defective layer covering almost all the surface of the nitrided case and a structure with segregations bands. The authors analyzed the samples after plasma nitriding by means of the X-ray photoelectron spectroscopy, electron probe microanalysis, light microscopy and microhardness measurements, for a better understanding of phenomena taking place at the industrial plasma nitriding of steels as well as more accurate valuation of the technological parameters of this thermo chemical treatment. The post processing validation is usually executed via the long 


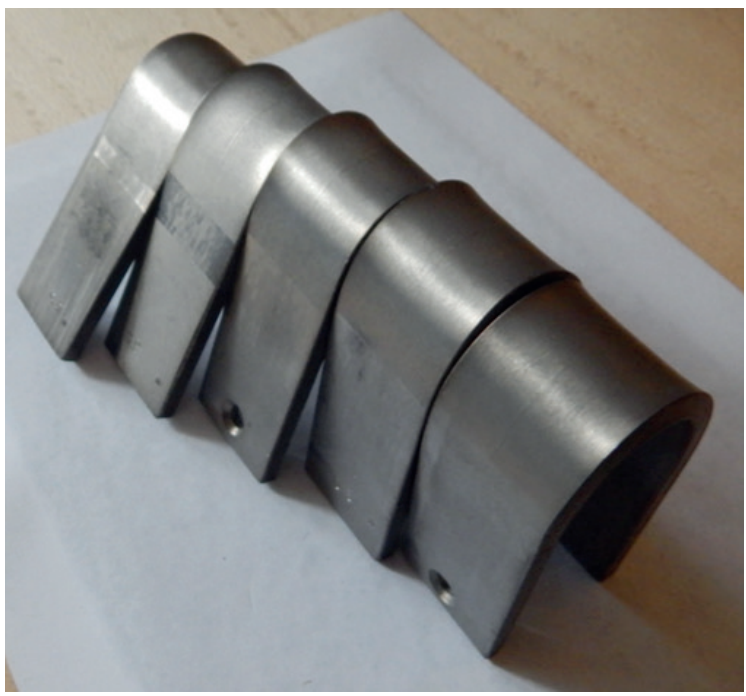

Figure 1 Samples after bending

term and high costs destructive tests, such as metallographic observations, micro indentation and application of the SEM, XRD or other techniques. Being so, any reliable non destructive concept, developed for such purpose, would be beneficial.

One of the possible aspects of the plasma nitriding process is preparation of the surface prior to plasma nitriding. Expressed in other words, samples history - especially the surface state - could vary due to micro and macro geometry, as well as the surface hardening, intensity of mechanical and thermal load, corresponding dislocation density, density of crystalline lattice defects or microstructure. Industrial experience indicates that for instance components undergoing intensive plastic deformation (for instance bending) could suffer from unstable compound layer, as well as the lower hardness of diffusion layer, when the consecutive plasma nitriding process is carried out after bending.

It is well known that the Bloch Walls (BWs) in ferromagnetic bodies, during their motion, interfere with all the crystalline defects such as grain boundaries, dislocation cell, precipitates as well as other non ferromagnetic phases [7-12]. The compound layer, entirely composed of nitrides, should be considered as the non ferromagnetic region progressively decreasing the magnetic Barkhausen noise $(\mathrm{MBN})$ received on the free surface along with gradual increase in its thickness. Moreover, the fine nitrides, embedded within the diffusion layer, strongly pin the BWs thus contributing to the lower MBN emission [13-15]. Being so, the $\mathrm{BN}$ technique would be promising method for the non destructive post processing monitoring of nitriding (focused on plasma nitriding in this study). The BN originate from irreversible and discontinuous BWs motion and the BN emission is strongly related to microstructure state, as well as to the stress state. The plasma nitriding process remarkably alters the microstructure in the diffusion layer since it establishes very fine nitrides hindering the BWs motion. Thus, the different density of nitrides would affect the MBN emission.

A concept in which components after the plasma nitriding process could be monitored via the BN should be based on contrast between the high MBN emission, associated with reduced nitrides density, and vice versa. This paper discusses the potentials of the MBN technique for monitoring components

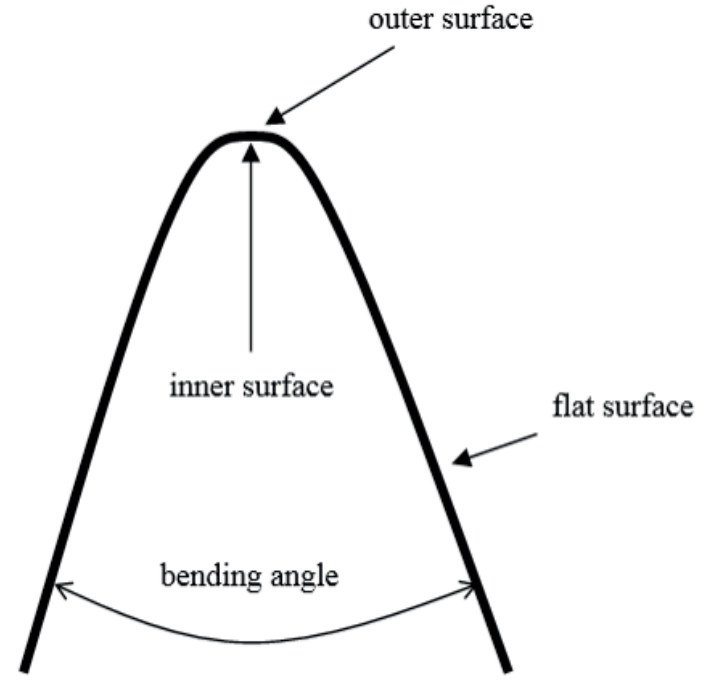

Figure 2 Brief sketch of the sample bending and analysed surfaces

of variable bending angle and the consecutive plasma nitriding process.

\section{Conditions of experiments}

The MBN measurement was performed by use of the Rollscan 350 device and software package $\mu \mathrm{Scan}$ in the frequency range of 10 to $1000 \mathrm{kHz}$ (magnetizing frequency $125 \mathrm{~Hz}$, magnetizing voltage $5 \mathrm{~V}, 10$ bursts and therefore 5 magnetizing cycles). The magnetic measurements were carried out in the axial direction (direction perpendicular to the direction of bending stress). Estimated sensing depth is about $50 \mu \mathrm{m}$.

The Vickers microhardness readings were conducted by the Härteprüfgerät EMCO N3D micro-hardness tester by applying force of $50 \mathrm{~g}$ for 10 seconds. Microhardness was determined by averaging 3 repetitive measurements ( 3 microhardness profiles spaced $0.1 \mathrm{~mm}$ ). To reveal the microstructure transformation, induced by the nitriding process, $20 \mathrm{~mm}$ long pieces were routinely prepared for metallographic observations (hot molded, ground, polished and etched by $3 \%$ Nital for 10 seconds). Four series of flat samples $(150 \times 30 \times 4 \mathrm{~mm})$ were made of steel $16 \mathrm{MnCr} 5$. Each series contains 5 samples bended on variable bending angle in the range $0 \div 90^{\circ}$ as Figure 1 illustrates. Figure 2 shows the analyzed areas on the samples. The first series was bent; the second one was annealed in the furnace at temperature $650^{\circ} \mathrm{C}$ for 2 hours. The third series was annealed after bending and plasma nitrided afterwards. The last series was only plasma nitrided after bending. the plasma nitriding process was performed at temperature $485^{\circ} \mathrm{C}$ for 8 hours.

\section{Results of experiments}

Figure 3 illustrates metallographic observation of bent surfaces for two different bending angles. It is obvious that the surface matrix is strained in direction of the applied stress. It is well known that the dislocation slip is initiated as soon as the yield stress of the material is exceeded. Increasing intensity of 


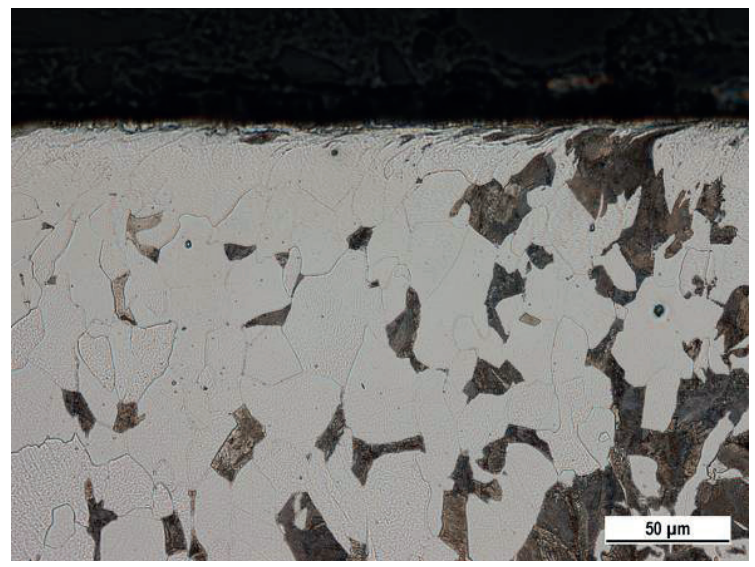

a) bending angle $90^{\circ}$

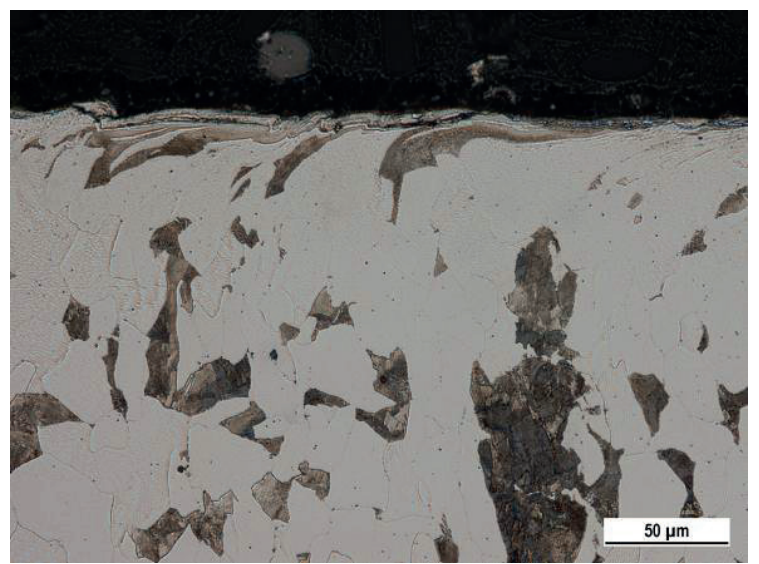

b) bending angle $0^{\circ}$

Figure 3 Metallographic images of surface after bending - the inner surface

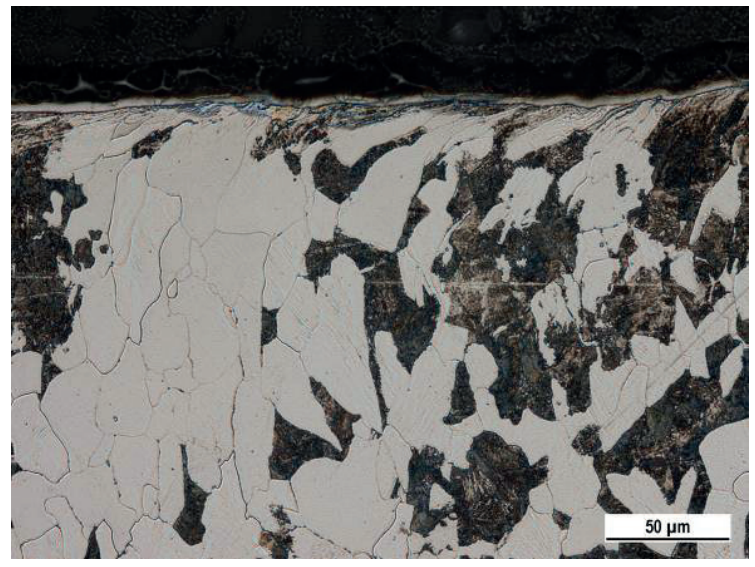

a) bending angle $90^{\circ}$, after nitriding

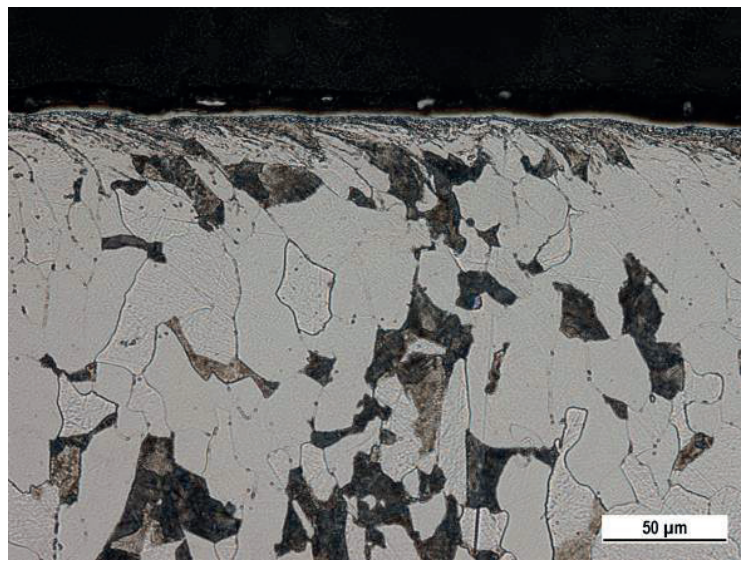

b) bending angle $90^{\circ}$, after annealing + nitriding

Figure 4 Metallographic images of the inner surface

bending (plastic deformation) increases dislocation density in the deformed surfaces. Therefore the thickness of the layer affected by plastic deformation increases together with plastic strain. Such behavior takes place when bending angle is increasing from $90^{\circ}$ up to the $0{ }^{\circ}$. The bending process produces tensile stresses in the outer surface of the samples, whereas the inner one is compressed. For this reason, unstressed samples contain compressive residual stresses in the outer surface and tensile residual stresses in the inner surface.

Increasing bending angle from $90^{\circ}$ up to the $0^{\circ}$ increases density of the lattice defects (especially dislocation density). Increasing dislocation density and the transformation processes affect the consecutive plasma nitriding process in two contradictory effects. The first one enhances nitrides to be embedded in the matrix since dislocation cells are clustered by vacancies as preferential sites for nitrides. The second effect hinders embedding nitrides in the matrix, as soon as the density of lattice defects exceeds the critical threshold.

Metallographic observation of the outer, as well as inner surfaces, after the plasma nitriding process and combination of annealing + nitriding is depicted in Figures 4 and 5. These images illustrate thin compound layer entirely composed of nitrides, which appears as white. The underlying structure represents the mixture of the steel matrix and very fine nitrides. However, the nitrides are very fine and cannot be seen on metallographic figures (neither on the SEM scans). The detailed analysis indicates that the thickness of compound layers for the inner and outer surface, as well as for variable bending angles, is similar (see also Figures 6 and 7) and varies in the range from 1 up to $3.5 \mu \mathrm{m}$.

From the MBN point of view, the compound layer is considered as a non-ferromagnetic layer not contributing to the MBN received by the pick-up coil on the free surface. Moreover, thickness of the compound layer is much less than that of the MBN sensing layer (about $50 \mu \mathrm{m}$ ). The compound layer is therefore considered as the gap between the pick-up coil and the steel matrix. This layer contributes to the MBN signal attenuation, as well as makes the magnetic field in the steel matrix weaker.

Certain differences can be found considering microhardness of the diffusion layer (see Figure 8). On one hand, the microhardness in the deeper region is slightly lower for only nitrided samples. On the other hand, the difference in the microhardness increases in the near the surface layer, thus in the bending affected zone and the MBN sensitive layer.

Figure 9 depicts that the flat surface exhibits nearly the same MBN emission. Such a behavior is associated with the fact that these surfaces remain unaffected by the bending process. Therefore, annealing does not take a significant role in the consecutive plasma nitriding process. On the other hand, Figures 


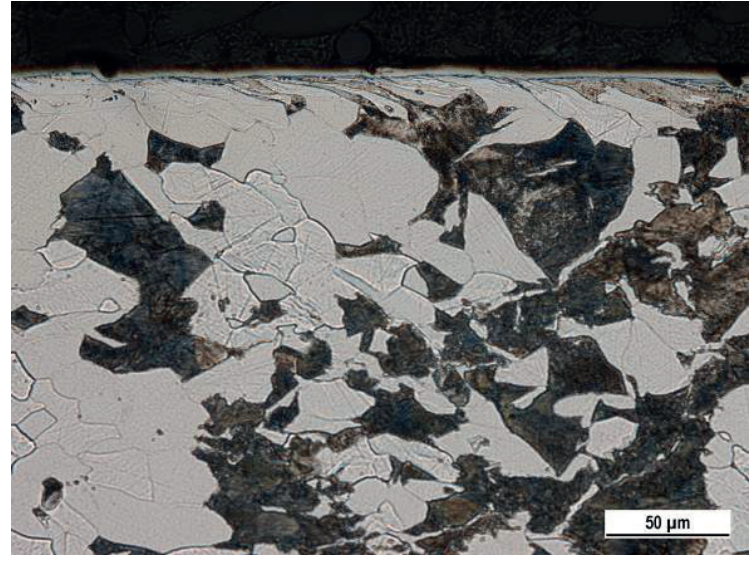

a) bending angle $90^{\circ}$, after nitriding

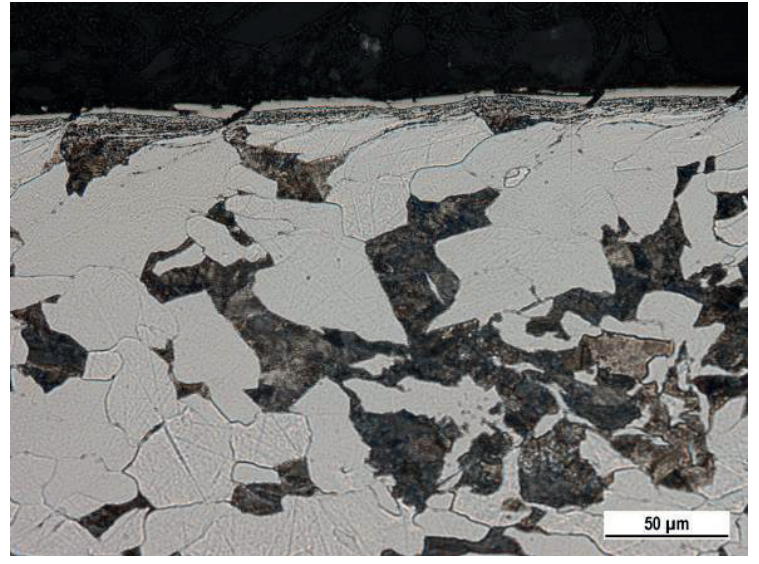

b) bending angle $90^{\circ}$, after annealing + nitriding

Figure 5 Metallographic images of the outer surface

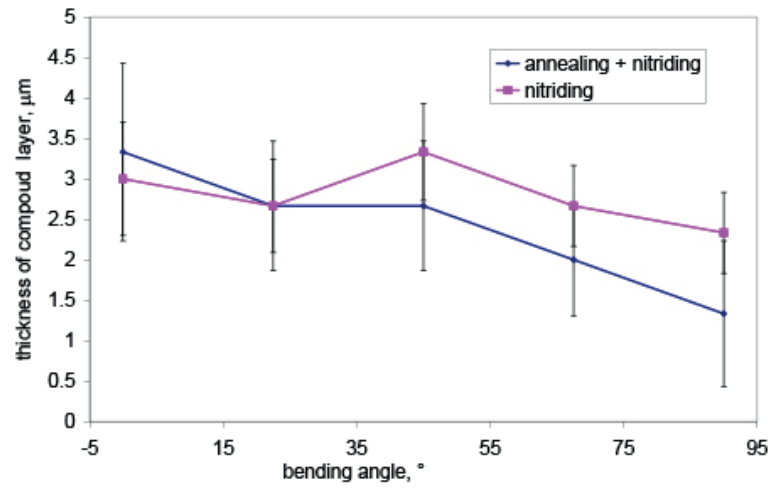

Figure 6 Thickness of the compound layer versus the bending angle the inner surface

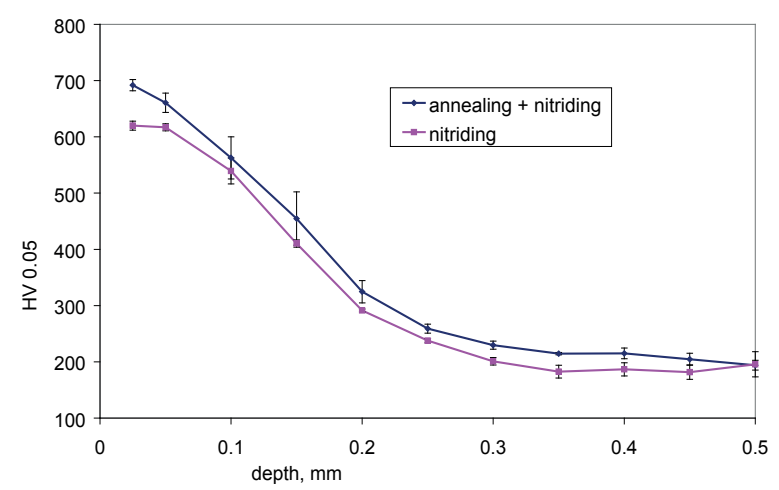

Figure 8 Microhardness profiles for the inner surface, bending angle $90^{\circ}$

10 and 11 clearly show that the MBN emission for annealed + nitrided surfaces is remarkably lower than for the surface undergoing only the nitriding process after bending.

As it was mentioned above, the compound layer does not contribute to the MBN emission received on the free surface. Being so, the differences between the MBN values, considering the different regimes of the heat treatment, should be associated with the diffusion matrix as the region below the compound layer. Its properties can be easily expressed in term of microhardness, since the hardness of a body after nitriding is driven by the density

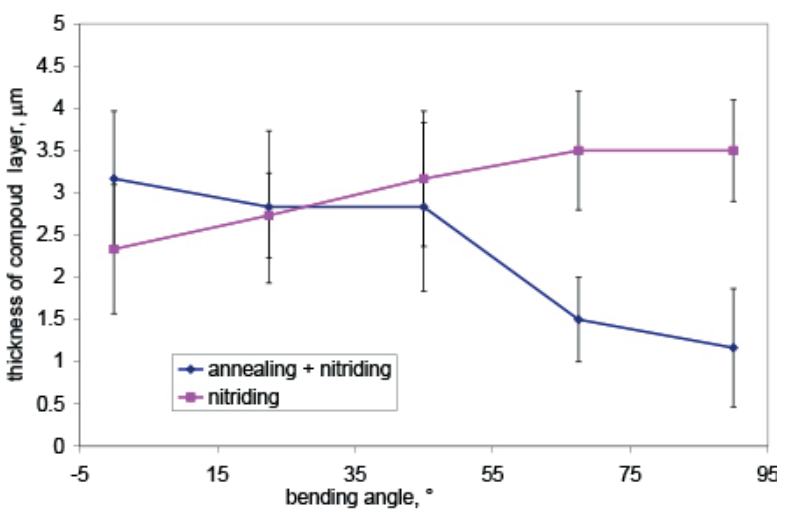

Figure 7 Thickness of the compound layer versus the bending angle the outer surface

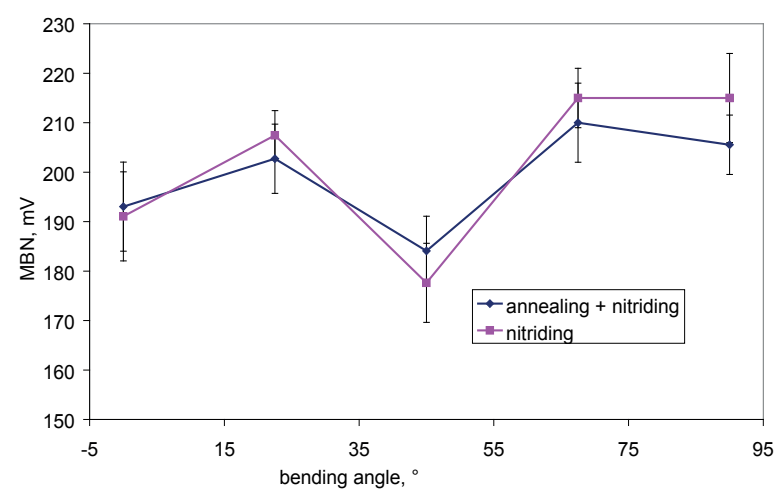

Figure $9 M B N$ versus the bending angle - flat surface

of the nitrides. Nitrides in the matrix strongly hinder the domain walls motion. For this reason, the lower MBN emissions for annealed + nitrided samples are attributed to the higher density of nitrides, which in turn corresponds to the higher microhardness on the matrix. Such finding can be supported by the number of the MBN pulses as they are illustrated in Figure 12. These pulses more or less correspond with the density of nitrides and therefore number of collisions of domains walls with these nitrides [13]. It can be clearly found that the number of detected MBN pulses for only nitrided samples is lower than that for annealed and nitrided 


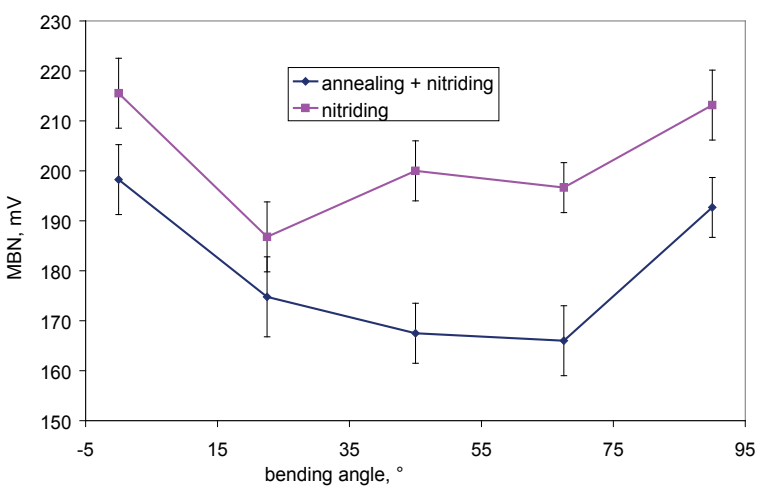

Figure $10 M B N$ versus the bending angle - inner surface

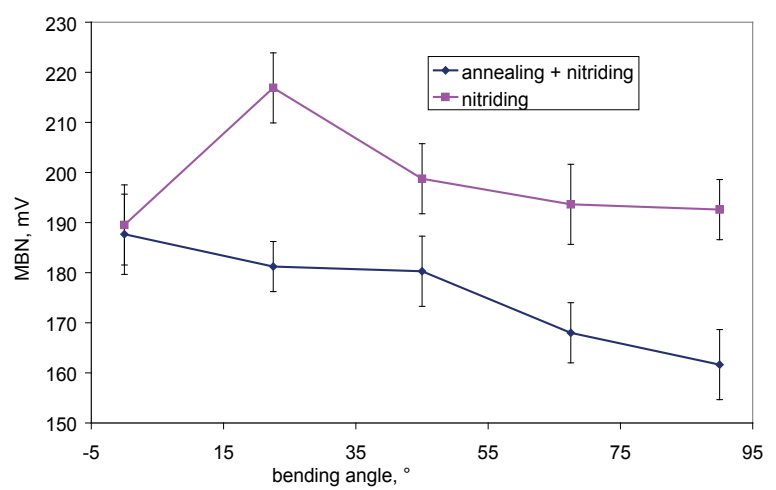

Figure $11 M B N$ versus the bending angle - outer surface

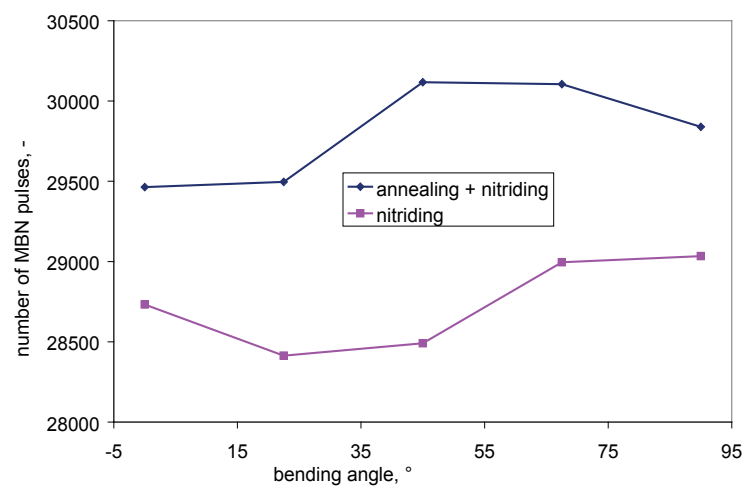

Figure $12 M B N$ pulses versus the bending angle - the inner surface

samples. It seems that annealing before nitriding process can contribute to the higher hardness of the diffusion layer and can be easily and directly measured via the MBN technique.

Figures 10 and 11 also demonstrate that the influence of the bending angle and therefore intensity of the plastic deformation on the nitriding process is complicated. The inner surface does not exhibit monotonous evolution of the MBN against the bending angle. On the other hand, the MBN values tend to increase with increasing intensity of the plastic deformation (when the bending angle decreases from $90^{\circ}$ to $0^{\circ}$ ).

\section{Conclusions}

It is necessary to notice that other BN parameters (except conventional rms value) could be potentially extracted from the raw $\mathrm{BN}$ signal as well and used for the non destructive monitoring of surfaces such as MBN envelopes, position of envelope maximum, number of the BN pulses, etc. This is only the pilot study focused on monitoring surfaces after the plasma nitriding and further analysis will be carried out in the near future. However, this study indicates that the MBN emission is a promising technique for monitoring of components after the nitriding process.

\section{Acknowledgement}

This study was supported by the VEGA project n. 1/0121/17 and KEGA project n. 008ZU-4/2018.

\section{References}

[1] TOTTEN, G. E. Steel Heat Treatment. 2nd ed. Oregon: Taylor\&Francis Group, 2006. ISBN 9780849384554

[2] MIRJANI, M., et al. Investigation of the effects of time and temperature of oxidation on corrosion behavior of plasma nitrided AISI 4140 steel. Surface \& Coatings Technology [online]. 2012, 206(21), p. 4389-4393. ISSN 0257-8972/eISSN 1879-3347. Available from: https://doi.org/10.1016/j.surfcoat.2012.04.064

[3] ATAPOUR, M., ASHRAFIZADEH, F. Cyclic oxidation of plasma nitrided valve steels. Physics Procedia [online]. 2012, 32, p. 853-860. ISSN 1875-3892/eISSN 1875-3892. Available from: https://doi.org/10.1016/j.phpro.2012.03.646 
[4] NADDAF, M., et al. Nitridation of steel using a microwave ECR plasma. Vacuum [online]. 2002, 64, p. 163-168. ISSN 0042207X/eISSN 1879-2715. Available from: https://kundoc.com/pdf-nitridation-of-steel-using-a-microwave-ecr-plasma-html

[5] MAROT, L., et al. Improved nitrogen transport in Fe-C alloys during $\mathrm{NH}_{3}$ plasma nitridation. Materials Letters. 2000, 44, p. 35-38. ISSN 0167-577X/eISSN 1873-4979.

[6] FLORI, M., et all. (2008). EPMA and microstructural analysis of a defective industrial plasma-nitrided steel. Surf. \& Coat. Technol. 202, pp. 5887-5894.

[7] MOORTHY, V., et al. Evaluation of heat treatment and deformation induced changes in material properties in gear steels using magnetic Barkhausen noise analysis. Conference ICBM 03 : proceedings. Tampere, Finland, 2001, p. 63-84.

[8] RANJAN, R., et al. Magnetic properties of decarburized steels: An investigation of the effects of grain size and carbon content. IEEE Transactions on Magnetics [online]. 1987, 23(3), p. 1869-1876. ISSN 0018-9464. Available from: https://doi. org/10.1109/TMAG.1987.1065175

[9] CIZEK, J., et all. Modification of steel surfaces induced by turning: non-destructive characterization using Barkhausen noise and positron annihilation. Journal of Physics D: Applied Physics. 2014, 47(44), p. 1-17. ISSN 0022-3727/eISSN 1361-6463.

[10] NESLUSAN, M., et al. Monitoring of grinding burn via Barkhausen noise emission in case-hardened steel in large-bearing production. Journal of Materials Processing Technology [online]. 2017, 240(C), p. 104-117. ISSN 0924-0136/eISSN 1873-4774. Available from: https:// doi.org/ 10.1016/j.jmatprotec.2016.09.015

[11] MICUCH, M., et al. Micro magnetic study of cutting conditions and grinding wheel wear influence on surface integrity. Manufacturing Technology. 2014, 14(1), p. 66-71. ISSN 1213-2489.

[12] NESLUSAN, M., et. al. Application of Barkhausen noise for analysis of surface integrity after hard turning. Manufacturing technology. 2012, 12(12), p. 60-65. ISSN 1213-2489.

[13] FARDA, R. Vplyv rezimu tepelneho a chemicko-tepelneho spracovania na emisiu Barkhausenovho sumu (Impact of the thermal and chemical-heat treatment regime on the emission of Barkhausen noise). Zilina, KOVT SjF ZU, 2017.

[14] NESLUSAN, M., et. al. (2015). Barkhausen noise Emission in milled Surfaces. Communications - Scientific Letters of the University of Zilina [online]. 2015, 17(3), p. 57-61. ISSN 1335-4205/eISSN 2585-7878. Available from: http://komunikacie. uniza.sk/index.php/communications/article/view/447

[15] DUBEC, J., et al. Influence of tool workpiece interface on surface integrity after turning. Communications - Scientific Letters of the University of Zilina [online]. 2014, 16(3A), p. 200-205. ISSN 1335-4205/eISSN 2585-7878. Available from: http:// komunikacie.uniza.sk/index.php/communications/article/view/567 